\title{
Os Caminhos do Pavão, Pavãozinho e Cantagalo
}

\author{
Camila Moraes*
}

\begin{abstract}
Resumo: $O$ trabalho versa sobre a implementação do Projeto Turismo no Museu de Favela, em andamento no Complexo de favelas Pavão, Pavãozinho e Cantagalo. O projeto surge após a fundação da organização não-governamental Museu de Favela (MUF), constituída por moradores das comunidades, com o objetivo de valorização da memória coletiva. Para a promoção de visitas ao museu pensaram em aliar sua proposta ao Turismo, em função da localização das favelas e do interesse por turistas em visitá-las. Deste modo, foi elaborado em convenio com o Programa de Aceleração do Crescimento (PAC) e com a Universidade Federal do Estado do Rio de Janeiro (UNIRIO) um curso de extensão em Turismologia para a comunidade capacitar-se para a organização de visitas e elaboração de roteiros nas favelas. Como turismóloga responsável pelo projeto, estou analisando, em trabalho de campo, a construção dos roteiros pelos alunos, as escolhas dos caminhos por onde vão passar os turistas, como eles imaginam a favela e o que eles querem mostrar. Nos caminhos do Pavão, Pavãozinho e Cantagalo há muitas histórias, muitos conflitos. Tudo o que os moradores querem é serem vistos, serem lembrados, e estão encontrando no Turismo e no Museu de Favela esta oportunidade.
\end{abstract}

Palavras-Chave: Turismo, Favelas, Museu, Políticas Públicas.

Abstract: The paper analyses the implementation of the Tourism Project at the Museum of Favela, underway in the complex of slums Pavão, Pavãozinho and Cantagalo. The project comes after the founding of the non-governmental Museum of Favela (MUF), consisting of the community residents, with the aim of recovery of the collective memory. For the promotion of sight-seeing to the museum it was thought to link this proposal worth tourism, due to the location of the slums and the interest of tourists to visit them. Thus it was produced through an agreement between the Acceleration Program (PAC) and the Federal University of the State of Rio de Janeiro (UNIRIO) an extension course in Turismologia to enable the community to be able to organize visits to the Route slums. As a turismóloga responsible for the project I am examining, on the field work, the construction of road maps by pupils, the choice of paths where tourists will go, their impression about the slum and what the community would like to show. In Pavão, Pavãozinho and Cantagalo there are many stories and conflicts. All that residents want is to be seen and remembered, and are finding in Tourism and the Museum of Favela this opportunity.

Keywords: Tourism, Slums, Museum, Public Policy.

Résumé: Le document traite de l'éxécution des projets Tourisme au Musée de la Favela, en cours dans les bidonvilles complexes Pavão, Pavãozinho et Cantagalo. Le projet vient après la fondation de l'organisation non gouvernementale Musée Favela (MUF), composée de résidents de la collectivité, avec l'objectif de récupération de la mémoire collective. Pour la promotion des visites

*Camila Maria dos Santos Moraes é mestranda do Programa de Pós-Graduação em Ciências Sociais da Universidade do Estado do Rio de Janeiro (PPCIS/UERJ). 
au musée, l'organisation a pensé d'associer sa proposition au tourisme en fonction de l'emplacement des taudis et l'intérèt des touristes pour y visiter. Ainsi, pour permettre à la communauté l'organisation de visites et la préparation des routes des bidonvilles, un cours de Tourismologie a été produit grâce à un accord avec le programme d'accélération de l'accroissement (PAC) et l'Université Fédérale de l'État de Rio de Janeiro (UNIRIO). Comme tourismologue responsable du projet, j'examine, dans le travail de terrain, la construction de routes de tourisme par les élèves, la choix des sentiers où les touristes pourront passer, comment les élèves de la communauté imaginent le bidonville et qu'est qu'ils y veulent montrer. Dans les voies du Pavão, Pavãozinho Cantagalo il y a beaucoup d'histoires et de nombreux conflits. Tout ce que les résidents veulent c'est d'être vus, d'être rappelés, et ils trouvent dans le tourisme et le Musée de la Favela cette opportunité.

Mots-clés: Tourisme, des taudis, de musée et des politiques publiques.

\section{Introdução}

Segundo estudos de Freire-Medeiros e Menezes (2006), o Turismo de Favela, não é uma prática de hoje. Relatos de viajantes, que visitaram o Rio de Janeiro nas primeiras décadas do século XX, revelam que visitar favelas cariocas não é uma prática que surgiu recentemente.

A visitação da Rocinha ocorre com finalidade turística desde a década de 1990, sua localização, grandiosidade e movimentação econômica despertam o interesse da sociedade e dos turistas.

O mercado desta segmentação tem se expandido para outras comunidades cariocas. No Morro da Babilônia, a exemplo do que acontece na Rocinha, são realizados tours pela localidade, com características distintas. Nesta, as visitas são organizadas por agentes internos como uma forma de desenvolvimento sustentável para a comunidade, sem permitir a interferência de agentes externos (FREIRE-MEDEIROS E MENEZES, 2006).

No Morro dos Prazeres há ao mesmo tempo uma colaboração e disputa entre agentes internos e externos que tentam organizar tours no local. O foco dessa experiência é a dimensão artística da favela (FREIRE-MEDEIROS E MENEZES, 2006).

No Morro da Serrinha existe um projeto de criação de outro corredor de visitação, que visa os aspectos culturais relacionados ao samba, jongo e manifestações religiosas ligadas à cultura africana como a umbanda (OMENA, 2009).

Pereira da Silva é outro morro que tem como estratégia turística o funcionamento de uma pousada com cinco unidades habitacionais, todas com sacadas que permitem a contemplação de belas paisagens. Em Vila Canoas, a hospedagem se dá de forma distinta. Os moradores hospedam os turistas em suas próprias casas (OMENA, 2009). 
A Casa de Cultura, localizada na Maré, foi criada em 2006 e possui um acervo formado por materiais pertencentes aos moradores da favela, objetivando a preservação do patrimônio cultural das periferias (OMENA, 2009). No ano de 2009, o Museu ganhou sinalização turística às margens das Linhas Vermelha e Amarela, Avenida Brasil, importantes estradas do estado do Rio de Janeiro que dão acesso à comunidade.

No Morro da Providência o turismo foi idealizado com a criação do Museu a Céu Aberto pelo Poder Público, que promoveu a recuperação de pontos históricos (MENEZES, 2008). Este projeto foi resultado da ação integrada do Programa Favela-Bairro e do Projeto de Desenvolvimento e Revitalização da Área Portuária, ambos realizados pela Prefeitura Municipal do Rio de Janeiro.

Menezes (2008) em sua dissertação de Mestrado destaca a especificidade do projeto do Museu da Providência dentro do contexto de revitalização da Zona Portuária e planejamento estratégico da cidade que o diferencia de outros museus em favelas, como por exemplo, o Museu da Maré.

Segundo Freire-Medeiros (2006) O Museu da Maré pode ser pensado como "um museu para dentro", ou seja, para os próprios moradores da favela; enquanto que o Museu da Providência foi planejado como um "museu para fora", para os turistas, para a visitação externa, para "gerar o contágio da cidade com a favela".

No ano de 2009, o Programa de Aceleração do Cescimento (PAC), o Museu de Favela e a Universdade Federal do Estado do Rio de Janeiro (UNIRIO) deram início ao Projeto Turismo no MUF (TURISMUF) que tem como proposta a capacitação da população local para o envolvimento na ativiade turística.

O projeto é considerado a concretização de um debate que vem sendo desenvolvido na comunidade desde 2008. Em busca de uma "vocação econômica" para o local, encravado entre Copacabana e Ipanema, bairros com forte apelo turístico, a comunidade se redescobriu como uma área cultural de talentos para a arte, que desenvolve música, dança e artesanato. Surgindo então, um movimento de reafirmação da identidade coletiva e de recomposição da memória de uma comunidade que existe há cerca de cem anos (MUSEU DE FAVELA, 2009). O MUF é o primeiro museu territorial integral do Brasil. Instalado no complexo de favelas Pavão, Pavãozinho e Cantagalo.

Segundo Scheiner (2009), um Museu Territorial é um tipo de museu que articula a paisagem e a comunidade através de qualquer tipo de relação entre sociedade e natureza na produção da cultura. Deste modo, o MUF pretende desenvolver um trabalho de 
mobilização da comunidade e ao mesmo tempo tornar-se uma atração turística, aproveitando esta articulação paisagem e comunidade que atrai tantos turistas para as favelas do Rio de Janeiro

Neste sentido, o Museu de Favela nasce com uma perspectiva que une os objetivos do Museu da Maré e do Museu da Providência. Seu conselho diretor pretende voltar o museu para os públicos internos e externos. Internamente mobilizando a comunidade e externamente atraindo turistas.

Neste artigo analiso a organização não-governamental (ONG) Museu de Favela (MUF) e o planejamento de suas visitas turísticas, um dos principais projetos da ONG, que está acompanhando uma tendência mundial de turismo em áreas pobres, que no Rio de Janeiro acontece nos espaços das favelas.

Este estudo é resultado do trabalho de campo realizado na comunidade, que teve início em Junho de 2009 no Primeiro "Visitão" organizado pelo MUF e pela UNIRIO; nas minhas participações no Projeto TURISMUF, em aulas dadas aos moradores das comunidades; e nas reuniões da diretoria da MUF.

\section{1 - O Projeto Turismo no Museu de Favela (TURISMUF)}

Este ano comecei a participar de um projeto que me encantou, o Projeto TURISMUF no Complexo de favelas Pavão, Pavãozinho e Cantagalo. Este projeto tem a proposta de atrair turistas para a região, possibilitando a geração de renda para a comunidade local.

Para entendermos este projeto precisamos identificar alguns de seus atores e como surgiu esta idéia de turismo no Museu de Favela.

O MUF começou como um vento de idéias de moradores insatisfeitos com o estado das coisas e com muita motivação e energia para promover mudanças. (http://www.museudefavela.com.br).

Segundo o jornal de apresentação do MUF, o Museu foi formado com a integração de moradores das comunidades do Pavão, Pavãozinho e Cantagalo e trabalha pela realização de um "plano cívico comum", "traz uma visão de futuro transformadora das 
condições de vida na favela", através da valorização da memória cultural coletiva e do desenvolvimento territorial e turístico (MUSEU DE FAVELA, 2009).

Assim, segundo informações encontradas no site e no jornal do MUF (2009) que surgiu a visão de futuro que se tornou o macro-objetivo do MUF:

Transformar o morro em um Monumento Turístico Carioca da História de Formação de Favelas, das Origens Culturais do Samba, da Cultura do Migrante Nordestino, da Cultura Negra, de Artes Visuais e de Danças Um grande roteiro de visitação turística nacional e internacional da Cidade do Rio de Janeiro. (MUSEU DE FAVELA, 2009).

Foi em meio a tantas idéias que o MUF constituiu-se enquanto ONG com estatuto, diretoria, sócios fundadores e um Conselho Comunitário aberto para a participação de todos os projetos e trabalhos realizados na comunidade.

No jornal de apresentação do Museu de Favela (2009) encontrei também o depoimento de uma ilustre moradora, Rita de Cássia, do morro do Cantagalo que conta porque o MUF foi formado:

O Rio de Janeiro oferece ao turista beleza natural e pontos turísticos reconhecidos internacionalmente, mas em meio a este cenário estão as favelas, consideradas por muitos como guetos, associados só a violência e a miséria". Contudo aos olhos de seus moradores, as favelas são locais com uma riqueza histórica e cultural a ser descoberta por aqueles que nunca se permitiram conhecê-la de perto. É pensando nisto que as comunidades do Cantagalo, Pavão e Pavãozinho tem a meta de se tornar um dos principais destinos de visitação turística do Rio, aproveitando que estão entre os bairros de Ipanema e Copacabana, muito valorizados economicamente e onde se hospedam grande parte dos turistas que frequientam o Rio de Janeiro. (MUSEU DE FAVELA, 2009).

O MUF foi fundado em fevereiro de 2009, com apoio do PAC e de sua Base de Inserção Social, mais conhecida como BISU. É importante mencionar que em todos os PAC's de favelas do Rio de Janeiro há uma empresa atuando nas atividades de inserção social. Estas bases oferecem cursos como, por exemplo: formação para garçons, empreendedorismo, curso de manicure e cabeleireiro, entre outros. 
Porém, nas comunidades do Pavão, Pavãozinho e Cantagalo foi diferente. Segundo o responsável pelo PAC no Rio de Janeiro, Luiz Fernando Pezão, em discurso proferido na Aula Inaugural do Projeto TURISMUF, quando chegaram à comunidade e solicitaram uma reunião com o conselho comunitário - conselho consultivo formado por moradores da localidade - este conselho sugeriu o desenvolvimento do turismo na região, pois há cerca de 20 anos, segundo um dos sócios fundadores do Museu, turistas visitam as favelas do Pavão, Pavãozinho e Cantagalo. Por isso, o MUF sugeriu que fosse desenvolvida a atividade turística de forma organizada na área.

Visando atender a solicitação do MUF, a Kal, empresa responsável pelo BISU nessas comunidades elaborou o projeto do ano de 2009 com cursos voltados para o desenvolvimento turístico da região, aliado a valorização da cultura local.

Para isso, a Kal buscou o Professor Mario Chagas (UNIRIO / IBRAM), para auxiliar na formação deste Museu e sua institucionalização. Após a fundação do Museu, buscaram o Curso de Turismo da UNIRIO para o oferecimento de curso de formação de guias locais.

Nos primeiros contatos com o Curso de Turismo, os professores explicaram que a universidade não tem autorização para formar guias, e informaram que existem cursos específicos para isso. Diante disso, uma das professoras do departamento de Turismo, Tânia Omena (UNIRIO / ABBTUR) apresentou como contraproposta ao MUF: O Projeto Turismo no MUF (TURISMUF).

O TURISMUF é um projeto de extensão da UNIRIO, cujo objetivo é incentivar o turismo como atividade econômica nas comunidades, e capacitar os moradores para trabalharem com turismo, como guias locais. Este projeto busca preparar os moradores para a elaboração de roteiros e planejamentos capazes de incluir a comunidade local, conforme as orientações do Ministério do Turismo, em especial, do Programa de Regionalização.

Segundo definição do Ministério do Turismo $(2007)^{1}$, regionalizar é transformar a ação centrada na unidade municipal, para uma política pública mobilizadora de planejamento e coordenação, para o desenvolvimento turístico local, regional, estadual e nacional; de forma articulada e compartilhada. É, também, um esforço coordenado entre municípios, estados e países para ações de negociação, consenso, planejamento e organização social (BRASIL, 2007).

\footnotetext{
$\overline{{ }^{1} \text { http://institucional.turismo.gov.br/regionalizacao/ }}$
} 
Deste modo, o Ministério apóia ações com o objetivo de ampliação e qualificação do mercado de trabalho; diversificação da oferta turística; estruturação dos destinos; ampliação do consumo turístico no mercado nacional e aumento da inserção competitiva do produto turístico no mercado internacional (BRASIL, 2007).

Neste sentido, uma das principais diretrizes políticas do plano de regionalização é denominada "Roteiros do Brasil: mercado e inclusão social". É nesta diretriz que está fundamentado o projeto TURISMUF.

O Programa de Regionalização faz uma proposta de transformação produtiva com equidade, propõe inclusão social, envolvimento da comunidade local em processos de decisão, visando também maior geração de renda. Está aí seu potencial para a promoção da aceleração do crescimento local, indo ao encontro das diretrizes do PAC.

O TURISMUF - Turismo no Museu de Favela é um projeto que visa a implementação do Turismo de Base Local via o projeto denominado Espaços de Potencial Diferencial para o Desenvolvimento de Pólos Turísticos na Cidade do Rio de Janeiro. Este projeto surge da interseção de dois desafios articulados: a demanda de inserção social e profissional de jovens, especialmente os oriundos de famílias de baixa renda, e a necessidade de desenvolvimento sustentável do turismo em pólos diversos e diferenciados (OMENA, 2009).

O projeto foi aceito e apoiado pelo Governo do Estado, que assinou um convênio com a UNIRIO para colocar o projeto em prática.

Iniciado o projeto, uma das primeiras ações foi participar do primeiro "Visitão" visita guiada pelos membros do Conselho do MUF. Para esta visita, o Museu de Favela elaborou um roteiro para apresentar as Comunidades do Pavão, Pavãzinho e Cantagalo a alguns de seus convidados. Farei então um breve resumo do "visitão".

\section{2 - O "Visitão"}

O Primeiro Visitão foi uma visita guiada apenas para convidados com a participação e o guiamento da guia turística e diretora cultural do MUF - Silvia Perrone -, que também dirige outra ONG na comunidade e já leva turistas há mais de quinze anos para essas favelas.

Neste evento participaram também os alunos / moradores do curso de Turismologia, alunos do Curso de Turismo da UNIRIO e professores da UNIRIO, entre eles Tânia Omena 
(UNIRIO / ABBTUR) e Mario Chagas (UNIRIO / IBRAM).

Esta visita marcou minha decisão pela participação no Projeto de Extensão como voluntária e a escolha do projeto como meu objeto de estudo no mestrado do programa de Pós-Graduação em Ciências Sociais da Universidade do Estado do Rio de Janeiro (PPCIS / UERJ)

Este "Visitão" foi importante para o projeto TURISMUF e para a minha pesquisa por algumas razões. A primeira razão foi a oportunidade de ver pela primeira vez o que foi mostrado neste roteiro do MUF e me imaginar de fato em um museu, apenas em um formato diferente. Assim, com este meu "olhar" já direcionado para a idéia do museu pude perceber tudo o que era apresentado como patrimônio das comunidades, como parte da história do território e parte do Museu de Favela. A segunda razão foi o conhecimento prévio da proposta do MUF de se apresentar como um Museu de Favela e não um Museu da Favela, ou seja, a idéia é que o Museu não represente só o Pavão, Pavãozinho e o Cantagalo, mas todas as favelas do Rio de Janeiro, ou seja, este museu representará a cultura de favela. Assim, acompanhando este roteiro pude entender como eles pensam as favelas do Rio de Janeiro e como eles querem apresentar ou representar essas favelas. A terceira razão foi o fato de o primeiro "visitão" ter sido apresentado como um grande evento, com certos aspectos de inauguração. O que me deu a certeza de encontrar os grandes personagens desta história, os idealizadores do projeto juntos, apresentando o roteiro pensado por eles, e, sobretudo, conhecer o que o MUF apresentaria antes do Curso de Turismologia.

$\mathrm{O}$ roteiro tem início com uma visita à exposição inaugural do Museu de Favela "Despertar de Alma e De Sonhos - Pavão, Pavãozinho e Cantagalo", que é composta por 13 totens, cujo conteúdo foi produzido por moradores, em entrevistas feitas por diretores do MUF. Da exposição seguimos para o plano inclinado, onde a guia nos explicou que este plano foi construído após uma tragédia no natal de 1984, quando houve um desmoronamento. No local mais afetado pelo deslizamento, no caminho aberto, o então governador Brizola construiu o plano inclinado, onde um bonde facilita o acesso ao morro.

A maior parte dos convidados pegou então o bonde. Eu subi com os moradores as escadarias, para ouvir as histórias e tirar fotografias, mas, infelizmente, pelas escadarias não me deixaram fotografar nada. Isto porque, o turismo em uma favela exige o cumprimento de algumas regras fundamentais, entre elas, onde, quando e o que fotografar, o que não é muito diferente de um museu tradicional. 
Ao final da escadaria, chagamos a Quarta Estação, onde encontramos uma vista maravilhosa do Rio de janeiro - Praia de Copacabana - este foi o primeiro mirante indicado pelos moradores, local onde no futuro eles pretendem sinalizar para que os visitantes entendam que ali eles podem e devem fotografar.

Em seguida nos dirigimos para a casa de Dona Antônia, diretora da Rede MUF. Esta rede foi formada para a articulação de todos os artesãos da comunidade.

Dalí seguimos pelas vielas, no meio do caminho havia grafites do Presidente do Conselho do MUF - o Acme - e pintura Naif em tecido do Cristiano.

Enquanto admirávamos as artes plásticas locais, Mario Chagas, amigo, professor e apoiador do projeto, me explicava que eles planejavam montar vitrines a céu aberto para expor as artes visuais, mais ou menos como estavam expostas as obras do artista já internacionalmente conhecido.

Após esta pequena caminhada chegamos a um singelo anfiteatro improvisado, as arquibancadas eram os degraus das escadas das comunidades e o palco a entrada do bar do Dórico. Lá se apresentava um coral de crianças da comunidade - Harmonicanto - que cantavam músicas de Jorge Benjor falando das belezas do Rio e uma performance do rap do MUF por membros do Museu de Favela. Enquanto isso, outros moradores, a pedido do grupo do MUF, deixavam os convidados subir em suas lajes para admirar a vista.

Depois de um tempo de dispersão e admiração começamos a descer até um pátio O Terraço do Serafim - onde houve uma apresentação da Capoeira Corpo e Movimento e exposição de artesanato de moradores. Descemos pelas escadarias da Rua Amor Perfeito, no Pavão, passamos por uma igreja originalmente católica, mas que se tornou um bar, depois uma igreja evangélica, voltou a ser igreja católica, e então fechou.

Após a igreja, a visita foi encerrada, já na esquina de uma das principais ruas de Copacabana, o que foi uma surpresa para muitos que achavam que não estávamos tão perto assim do "asfalto".

\section{3 - O Visitão e a construção de novos signos para as favelas}

A partir deste momento, analisarei duas questões que me chamaram a atenção no "visitão". A primeira é como o MUF está utilizando a institucionalização deste Museu de Favela e do Turismo de Favela para fortalecer a identidade da comunidade e reafirmar sua cultura, sobretudo, sua etnicidade. 
Até os anos 80, segundo Leite (2008), a representação negativa da favela era contrabalanceada por sua valorização como berço do samba, do carnaval e da cultura popular. É nesta linha que vem se devolvendo os trabalhos no Museu de Favela na revalorização da favela como berço do samba, da cultura do migrante nordestino, da cultura negra. Isto porque, hoje as favelas são símbolos de marginalidade, desordem e violência. São estes signos de miséria e violência que motivaram a fundação do MUF e motivam a visitação às favelas do Rio de Janeiro.

Na Rocinha, uma placa com os dizeres: Rocinha: a peaceful Ana beautufu place Copacabana - Rio de Janeiro, chamou a atenção de Freire-Medeiros (2009), nela a favela é promovida como um local pacífico e belo assim como Copacabana, é verde e amarela simbolizando que as favelas são parte da nação, parte do Brasil. Assim de uma presença marginal a favela é transformada discursivamente em parte central da sociedade brasileira.

Segundo Freire-Medeiros (2009), os guias e as agências que atuam na Rocinha afirmam que o tour na favela transforma a reputação destas que são relacionadas apenas a violência e a pobreza. É esta dissociação da imagem da favela à violência e à miséria que motiva o MUF em sua promoção de visitas turísticas.

O primeiro fato que representou esta reafirmação no "visitão" foi o local escolhido para começar o roteiro - o plano inclinado. A princípio não entendi o porquê de contar a história da tragédia, se no discurso dos membros do MUF falava-se sempre em mostrar o que a favela tem de bom, os seus artistas e a sua cultura. Mas por outro lado, a escolha do plano inclinado para dar início ao roteiro é também funcional, já que este facilita a subida pela favela.

Além disso, o conselho do MUF pretende apresentar o patrimônio das favelas e seu significado para as comunidades. Por isso, a importância de contar a história do plano inclinado, pois, mesmo não sendo a melhor das lembranças da comunidade, esta história deve ser contada, porque também é uma historia de glória ao final. Houve o desmoronamento, mas ainda assim, as favelas estão lá até hoje, apesar de toda a reação da classe média na época, contra a obra na favela ao invés da remoção.

Acredito que contar este capítulo da história marca também uma posição; afinal todo este processo de fundação do Museu de Favela tem início com a chegada das obras do PAC de urbanização e regulamentação das casas que ali estão. Os moradores sabem que vivem em uma área valorizada da Zona Sul e temem perder suas casas. Deste modo, começar o roteiro mostrando que vinte cinco anos depois de uma tragédia, eles ainda estão 
ali é marcar uma posição de força.

Esta posição é aliada a toda a proposta do museu no sentido de fortalecimento da identidade local, da cultura local. Cultura esta representada pelos grafites que estão nas paredes em boa parte do roteiro, na pintura dos artistas em telas, na capoeira, no coral das crianças e no eco-artesanato da rede MUF.

Como podemos confirmar adiante no trecho do rap do MUF:

Samba, capoeira, dança de salão nesse caldeirão se mistura dentro da cultura

Etinografico, prático mundo pobre

Vivências, memórias e fatos que se descobrem

Os autores e precursores, construtores, mentores, pacificadores apaziguadores, colonizadores acendam os refletores

(...)

das vitórias, histórias, brasilidade, vista da laje e das extremidades testemunhos reais, tesouros marginais, dançai, cantai

Seus bens culturais

Sarafim, Pavãozinho, Cantagalo e Pavão, Vietnã, Caranguejo

Na conexão, Quebra Braço, Buraco Quente, Terrerão, Igrejinha, Nova

Brasília um rolézão, só chegar no brindão ser sangue bom

Povo anfitrião estende a mão

Aprecie as belezas que emanam dos jardins suspensos de Ipanema e Copacabana.

Museu de Favela é virtude de atitude sincera

Museu de Favela é galeria a céu aberto no beco e na viela

Museu de Favela é virtude de atitude sincera.

(RAP do MUF).

O rap nos mostra ainda uma busca pela etnicidade da favela pelo MUF. Os autores do Rap apropriaram-se da palavra etnográfico no rap, que apesar de aparecer com uma grafia diferente da forma correta, não está ali por acaso, o etnográfico remete a etnicidade.

Deste modo, o caso do MUF lembra em muitos aspectos a aldeia dos Pataxós, em Porto Seguro (GRUNENWALD, 2002). Os índios organizaram e re-significaram sua cultura para reforçar sua etnicidade, viver do turismo e participar da forte atividade turística da região. Passaram então a organizar apresentações culturais de seus rituais, danças, além de vender seu artesanato, possibilitando a manutenção da aldeia em um local turisticamente valorizado.

No MUF, o mesmo fato está acontecendo, basta lembrarmos do roteiro descrito anteriormente, os grafites apresentados, a apresentação de capoeira, o artesanato vendido ao final do roteiro. Guardadas suas especificidades, o caso dos pataxós e do MUF são semelhantes na medida em que ambos buscam o turismo como gerador de renda em cidades turísticas, respectivamente, Porto Seguro e Rio de Janeiro. Embasados pelo 
segmento do Turismo Cultural, mais especificamente, do Turismo Étnico, estas comunidades garantem assim, sua inserção na atividade turística. Por isso, o turismo aliado ao museu aparece para os moradores, em especial aqueles organizados no MUF, como estratégia de reafirmação da população naquele território.

A segunda questão analítica fundamental sobre o "visitão" se refere aos cuidados e aos conflitos entorno desta reafirmação do termo favela. Para a direção do MUF o turismo não é uma maravilha ou uma panacéia para todos os seus problemas. Sabem que o turismo atrai pessoas de fora dos territórios com interesse na exploração. Um exemplo deste fato muito mencionado pela direção do Museu de Favela e alguns moradores é a Rocinha; local identificado pelos membros do MUF como explorado turisticamente por pessoas de fora, e muitas vezes mencionado por eles como uma referência do que eles não querem que aconteça no Pavão, Pavãozinho e Cantagalo. Percebe-se aqui um dos conflitos mais recorrentes no Turismo - as tensões entre "os de fora" e os de "dentro" como já foi trabalhado por Prado (2003) na Ilha Grande.

Sobre os jipes, rejeitados pela direção do Museu de Favela, Freire-Medeiros (2009) explica que estes veículos são um ícone dos passeios turísticos na Rocinha, apesar de apenas três agencias utilizarem efetivamente este tipo de transporte. Os agentes de viagem e os guias justificam que o veículo aberto possibilita uma percepção mais acurada da paisagem da favela e não vêem fundamento para as criticas que acusam o jipe de inspirar a idéia de um "safári de pobres". Já outra agência a Favela Tour faz questão de anunciar que não realiza seu tour em jipes. Para o dono da agencia, o uso das vans é uma preocupação humanística, para conquistar turistas menos aventureiros e mais conscientes.

No Pavão, Pavãozinho e Cantagalo, muitos moradores, em especial aqueles integrantes da direção do MUF são veementemente contra os jipes, falam inclusive na vontade de redigir uma matéria para o jornal institucional do MUF explicando a posição do Museu de Favela contraria a entrada de passeios em jipes no complexo de favelas.

No jornal de apresentação do MUF um trecho já descreveu a idéia de rejeição a estes jipes, mas de forma indireta, a palavra jipe não aparece, mas aparece zoológico, que remete a safári e as analogias que muitos fazem a estes jipes:

Um dizia 'vamos fazer uma galeria aberta de grafites artísticos na comunidade', outro 'vamos fazer um documentário contando a historia do morro', outro 'vamos mostrar aos turistas que as favelas têm um lado 
melhor do que aquele que é mostrado em outras favelas onde sobem turistas e estrangeiros que acham que a favela é zoológico e morador é bicho.' (MUSEU DE FAVELA, 2009).

Entretanto ainda fica uma questão que merece ser ressaltada: os jipes são apenas um exemplo dos conflitos que acontecem e que vão acontecer no turismo no Museu de Favela. Não podemos negar que os turistas são atraídos pela imagem da favela que é divulgada na grande mídia; a imagem da miséria e da violência, esta é a pobreza turística apresentada por Freire-Medeiros (2009). No entanto, é contra esta imagem que se desenvolve o trabalho do Museu de Favela.

Estes conflitos na relação museus, turismo e re-significação de comunidades e populações já foram abordados em diversos trabalhos, entre eles no ensaio de Witz (2006) Transforming Museums on Postapartheid Tourist Routes (Transformando Museus no Pós Apartheid e Rotas turísticas).

Neste ensaio são levantadas questões referentes aos museus e centros culturais que receberam incentivos do governo de Mandela, Pós-Apartheid. Estes museus funcionam como importantes signos no desenvolvimento do discurso de redescoberta de uma herança, uma identidade, de reconciliação e construção de uma nação igualitária, com o objetivo de se tornarem também novas rotas turísticas no país.

No entanto, o modo como se apresentavam estes museus conflitava com as campanhas de divulgação que, desde a década de 20 , estavam voltadas para a visita a uma África Primitiva. O caso da África do Sul pode servir de inspiração para pensar o turismo em favelas, que apesar de não possuírem um histórico de campanhas turísticas oficiais como a África Primitiva, convivem com outro tipo de campanha na mídia, uma divulgação da violência e do tráfico.

Esta divulgação da violência nas favelas é conhecida pelos turistas, e é em oposição a estas campanhas deterioradoras da imagem das favelas que o MUF, como já foi apresentado, quer apresentar e representar as favelas. O Museu de Favela tem uma proposta semelhante aos Museus do Pós-Apartheid, na medida em que busca um distanciamento de signos deterioradores. No caso da favela o signo da violência e do tráfico de drogas.

Portanto, é importante termos em mente que na relação turismo e comunidade, os museus têm que constantemente mediar o passado, o presente e suas representações. Esta 
mediação está envolvida também em um circuito de imagens, signos e a economia do turismo internacional, bem como com o conflito entre as representações.

\section{REFERÊNCIAS BIBLIOGRÁFICAS}

ANDERSON, B. Comunidades Imaginadas - Reflexões Sobre a Origem e a Expansão do Nacionalismo. Edições 70. São Paulo, 2005.

BRASIL. Ministério do Turismo. Programa de Regionalização do Turismo. 2007.

Ministério do Turismo. Plano Nacional de Turismo (2007/2010) - Uma Viagem de Inclusão. Brasília, 2007.

FREIRE-MEDEIROS, B. Favela como Patrimônio da Cidade? Reflexões e polêmicas acerca de dois museus. Estudos Históricos (Rio de Janeiro), v. 38. 2006.

. Gringo na Laje. FGV. Rio de Janeiro. 2009

FREIRE-MEDEIROS, B. e MENEZES, P. A Construção da Favela Carioca como Destino Turístico in: Anais da 58ª Reunião Anual da SBPC - Florianópolis, SC, Julho. 2006.

GRÜNEWALD, R. A.. A Reserva da Jaqueira: Etnodesenvolvimento e Turismo. In: RIEDL, Mário; ALMEIDA, Joaquim A.; VIANA, Andyara L. B.. (Org.). Turismo Rural: Tendências e Sustentabilidade. Santa Cruz do Sul: EDUNISC, v. , p. 205-230, 2002

LEITE, Márcia Pereira . Violência, sociabilidade e risco nas margens da cidade: percepções e formas de ação de moradores de favelas cariocas. In: Luiz Antonio Machado da Silva. (Org.). Machado da Silva, Luiz Antonio (org.). Vida sob cerco: violência e rotina nas favelas do Rio de Janeiro. Rio de Janeiro: FAPERJ/Nova Fronteira, v. , p. 115-141, 2008.

MENEZES, P. Interseções entre novos sentidos de patrimônio, turismo e políticas públicas: Um estudo de caso sobre o Museu a céu aberto do Morro da Providência. Dissertação de Mestrado em Ciências Humanas: Sociologia - Instituto Universitário de Pesquisas do Rio de Janeiro, 2008.

MUSEU DE FAVELA. Primeiro Jornal Informativo do Museu de Favela. Rio de Janeiro, 2009.

MUSEU DE FAVELA. http://www.museudefavela.com.br

MACCANNELL, D. Reconstructed ethnicity: tourism and cultural identity in Third World communities. In: MacCANNEL, Dean. Empty meeting grounds. London: Routledge, p. 158-171, 1992. 
Shocken. 1992.

The Tourist: a new theory of the leisure class. Nova York,

OMENA, T. TURISMUF. Turismo no Museu de Favela. Projeto Extensão. UNIRIO, 2009.

PRADO, R. M. Tensão no paraíso: Aspectos da intensificação do turismo na Ilha Grande. Caderno Virtual do Turismo $\mathrm{n}^{\mathrm{o}}$ 7. Rio de Janeiro: Instituto Virtual do Turismo/COPPE/UFRJ, 2003.

SCHEINER, Tereza. Que amigos? Para que Museus. In: Revista Museu. Disponível em: www.revistamuseu.com.br/artigos/art_asp/?id1987/ Acessado em: 13/06/2009.

URRY, John. O Olhar do Turista: lazer e viagens nas sociedades contemporâneas. São Paulo: Nobel, 1990.

VALLADARES, Lícia do Prado. Que favelas são essas? Insight Inteligência. Rio de Janeiro, ano 2, n. 8, ago/out, pp. 62-68, 1999.

VAN DEN BERGHE, P L. The quest for the other: ethnic tourism in San Cristóbal, Mexico. Seattle: University of Washington Press, 1994.

VAN DEN BERGHE, P L.; KEYES, C F. Introduction: tourism and re-created ethnicity. Annals of Tourism Research, v. 11, p. 343-352, 1984.

VILLELA, Gustavo. O Aventureiro, Ilha Grande - RJ: Uma análise de mudança social. Tese de Doutorado apresentada ao Programa de Pós-graduação em Antropologia Social, Museu Nacional, da Universidade Federal do Rio de Janeiro, 2008.

WITZ, Leslie. Transforming Museums on Postapartheid Tourist Routes. In: Karp, I., Kratz, C., Szwaja, L. and Ybarra-Frausto, T. (eds). Museum Frictions: Public Cultures/Global transformations, Durham, North Carolina: Duke University Press, 2006.

WOOD, R E. Ethnic tourism, the State, and cultural change in Southeast Asia. In: Annals of Tourism Research, v. 11, p. 353-374, 1984. 